\title{
The Oxidation of Oleate in Submicron Aqueous Salt Aerosols: Evidence of a Surface Process
}

\author{
V. Faye McNeill, ${ }^{\dagger}$ Glenn M. Wolfe, ${ }^{\ddagger}$ and Joel A. Thornton ${ }^{*}, \dagger$ \\ Departments of Atmospheric Sciences and Chemistry, University of Washington, Seattle, Washington 98195
}

Received: September 22, 2006; In Final Form: November 14, 2006

\begin{abstract}
We have studied the oxidation of submicron aqueous aerosols consisting of internal mixtures of sodium oleate (oleic acid proxy), sodium dodecyl sulfate, and inorganic salts by $\mathrm{O}_{3}, \mathrm{NO}_{3} / \mathrm{N}_{2} \mathrm{O}_{5}$, and $\mathrm{OH}$. Experiments were performed using an aerosol flow tube and a continuous flow photochemical reaction chamber coupled to a chemical ionization mass spectrometer (CIMS). The CIMS was fitted with a heated inlet for volatilization and detection of organics in the particle phase simultaneously with the gas phase. A differential mobility analyzer/condensation particle counter was used for determining aerosol size distributions. The oxidation of oleate by $\mathrm{O}_{3}$ follows Langmuir-Hinshelwood kinetics, with $\gamma^{\mathrm{O}_{3}} \approx 10^{-5}$ calculated from the observed loss rate of oleate in the particle phase. The best fit Langmuir-Hinshelwood parameters are $k_{\max }^{\mathrm{I}}=0.05 \pm 0.01$ $\mathrm{s}^{-1}$ and $K_{\mathrm{O}_{3}}=4( \pm 3) \times 10^{-14} \mathrm{~cm}^{3} \mathrm{molec}^{-1}$. These parameters showed no dependence on the ionic composition of the aerosols or on the presence of alkyl surfactants. Several ozone oxidation products were observed to be particle-bound at ambient temperature, including nonanoic acid. We observed efficient processing of oleate

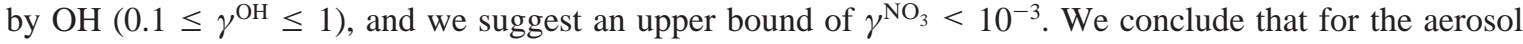
compositions studied, oxidation occurs near the gas-aerosol interface and that the 1 e-fold lifetime of unsaturated organics at the aerosol surface is $\sim 10 \mathrm{~min}$ due to $\mathrm{O}_{3}$ oxidation under atmospheric conditions. In the context of a Langmuir-Hinshelwood mechanism, different underlying aerosol compositions may extend the lifetime of oleic acid at the surface by reducing $K_{\mathrm{O}_{3}}$.
\end{abstract}

\section{Introduction}

Internal mixtures of inorganic and organic material are typical of tropospheric aerosols. ${ }^{1-11}$ Naturally occurring, surface-active fatty acids are common components of the organic fraction. ${ }^{12-15}$ Biological material at the sea surface, including fatty acids and unsaturated organics such as chlorophyll, may be incorporated into marine aerosols via bubble bursting. Little is known about the physical state of internally mixed aerosols, although inorganic aerosols with organic coatings have been observed, ${ }^{4-7,11}$ as well as organic particles with inorganic inclusions ${ }^{7}$ and gellike mixtures. ${ }^{8,9}$ Surface active molecules, such as fatty acids, may partition to the gas-aerosol interface of aqueous particles, lowering the surface tension and creating an organic surface layer. ${ }^{16-18}$ However, fatty acids and fatty acid salts also exhibit complex phase behavior that depends on temperature, $\mathrm{pH}$, and ionic content. ${ }^{19-21}$ The formation of liquid crystal phases may be important for fatty acids in atmospheric aerosols, as well as separation into aqueous and oil-like phases, which could result in an organic surface coating. ${ }^{19}$ Films can also develop on aqueous seed particles through condensation of semivolatile organics that are the oxidation products of unsaturated volatile organic precursors.

An organic surface layer on aqueous aerosol particles would be important as it can create a resistance to the transfer of gasphase species to and from the aerosol surface, thus affecting the particles' ability to act as cloud condensation nuclei (CCN) and their heterogeneous chemistry. ${ }^{22-25}$ Therefore, it is of

* To whom correspondence should be addressed. E-mail: thornton@ atmos.washington.edu.

Department of Atmospheric Sciences.

$\doteqdot$ Department of Chemistry. interest to understand the lifetime of organic surface films due to oxidation, as well as to explore the potential impacts of aged films on gas-aerosol mass transfer.

Atmospheric aerosols are exposed to oxidants such as the hydroxyl radical $(\mathrm{OH})$, ozone $\left(\mathrm{O}_{3}\right)$, and the nitrate radical $\left(\mathrm{NO}_{3}\right)$, leading to oxidation and possible shortening of carbon chains ${ }^{26,27}$ located at the surface. Ozone is a particularly efficient oxidant of unsaturated organics. The reaction of $\mathrm{O}_{3}$ with oleic acid (cis9-octadecenoic acid, $\mathrm{C}_{18} \mathrm{H}_{34} \mathrm{O}_{2}$ ), has been studied intensely in recent years. Oleic acid has been detected in urban, rural, and marine aerosols and is used as a marker for meat cooking in continental aerosol. ${ }^{12,28-36}$ Several factors have motivated these studies, including: quantifying the time scale for organic aerosol to be converted from hydrophobic to hydrophilic via oxidation thereby influencing their CCN ability, estimating the lifetime of unsaturated organics in aerosol particles, and evaluating organic aerosol oxidation as a potential source of volatile organics. The reaction has been studied using pure oleic acid aerosols, ${ }^{37-45} 2-30 \mathrm{~nm}$ thick films on polystyrene beads, ${ }^{46} \sim 1$ $\mu \mathrm{m}$ thick films on aqueous sea salt aerosol ${ }^{47}$ and on macroscopic films in coated wall flow tube studies. ${ }^{48-52}$ Both volatile and involatile products of oleic acid ozonolysis have been identified, including nonanaldehyde, nonanoic acid, 9-oxononanoic acid, and azelaic acid. ${ }^{38,46,48}$ It has also been suggested that ozonolysis may lead to polymerization in pure oleic acid particles ${ }^{41,42}$ and for other unsaturated organics in self-assembled monolayers ${ }^{53,54}$ and thin films. ${ }^{55}$

Overall, existing experimental data suggest that the reactive uptake coefficient, $\gamma^{\mathrm{O}_{3}}$, for $\mathrm{O}_{3}$ on pure oleic acid is on the order of $10^{-3}$ at room temperature..$^{37,38,40,48,50}$ This implies that the lifetime of oleic acid at the aerosol surface in the presence of 
$50 \mathrm{ppb} \mathrm{O}_{3}$ should be on the order of seconds, and that whole particle oxidation could take place in less than $1 \mathrm{~h}$ for pure submicron oleic acid particles. This efficient oxidation observed in the laboratory is somewhat in contrast with the fact that oleic acid is commonly observed in aged particles..$^{12,28,36}$ Furthermore, there remains considerable debate regarding the mechanism and kinetics of oleic acid oxidation at the gas-aerosol interface. It has been suggested from studies of macroscopic surfaces that the phase and morphology of the organic coating can affect the oleic acid oxidation efficiency. ${ }^{49,52,56}$ To our knowledge, there are no data available on the kinetics of oleate oxidation, or that of other alkenoic acids, in mixed organic-aqueous particles. It is possible that oleate in aqueous inorganic aerosols will exhibit different reaction kinetics and product formation than a pure oleic acid system, because oleate may exist in either a thin surface layer or in a separate organic subphase.

This work provides novel kinetic and mechanistic information for the oxidation chemistry of organic film-forming compounds in aqueous particles using real-time chemical ionization mass spectrometry for gas and particle composition measurements. Because aqueous aerosol particles can be highly ionic, nonideal solutions, extrapolating measurements from macroscopic systems to the submicron particle regime carries significant uncertainty. Using the relatively wide body of existing work related to the $\mathrm{O}_{3}$ oxidation of oleic acid in pure particles or macroscopic systems as a pivot, we have explored the $\mathrm{O}_{3}$ oxidation kinetics of submicron mixed aqueous - organic aerosols containing sodium oleate. On the basis of $\mathrm{N}_{2} \mathrm{O}_{5}$ uptake and $\mathrm{O}_{3}$ oxidation kinetics, we conclude that oleate oxidation occurs at the aerosol surface and that, due to the thinness of the surface layer relative to the reactive diffusive length, the oxidation of oleate in our particles is not as efficient as observed in pure oleic acid particles or macroscopic films. We also provide new kinetic measurements of $\mathrm{OH}$ oxidation of oleate in these particles and set an upper limit to the reaction rate of $\mathrm{NO}_{3} / \mathrm{N}_{2} \mathrm{O}_{5}$ with oleate in mixed aqueous particles. If sodium oleate is a proxy for oleic acid in particles containing water and inorganic ions, the overall lifetime of oleic acid is still likely to be short when subject to oxidation in the atmosphere, but the inferred mechanism implies the lifetime will depend on the partitioning of $\mathrm{O}_{3}$ to relevant atmospheric aerosol surfaces.

\section{Experimental}

Experiments were performed using an aerosol flow tube or a continuous flow photochemical reactor coupled to a custombuilt chemical ionization mass spectrometer (CIMS) featuring a heated inlet for volatilization of particle phase organics. A differential mobility analyzer/condensation particle counter (Grimm Technologies) was used for measuring aerosol size distributions and determining aerosol surface area. A schematic of the experimental setup is available in the Supporting Information.

Aerosol Generation and Characterization. Submicron aqueous sodium chloride $(\mathrm{NaCl})$ or sodium sulfate $\left(\mathrm{Na}_{2} \mathrm{SO}_{4}\right)$ aerosols were generated by atomizing a dilute salt solution $(0.05$ $\mathrm{M} \mathrm{NaCl}$, or $0.06 \mathrm{M} \mathrm{Na}_{2} \mathrm{SO}_{4}$ ) in deionized water using a commercial constant output atomizer (TSI). To create aerosol doped with sodium oleate, atomizer solutions with $10^{-3} \mathrm{M}$ sodium oleate were generated as follows: $0.0005 \mathrm{~mol}$ oleic acid were added to $500 \mathrm{~mL}$ of $0.001 \mathrm{M} \mathrm{NaOH}$ solution. After stirring for $\sim 1 \mathrm{~h}$, the oily oleic acid droplets were observed to go into solution, at which point the salt $\left(\mathrm{NaCl}\right.$ or $\left.\mathrm{Na}_{2} \mathrm{SO}_{4}\right)$ was added. The sodium oleate/salt solutions were diluted volumetrically with salt solution to achieve lower oleate concentrations for the
$\mathrm{N}_{2} \mathrm{O}_{5}$ uptake experiments. An atomizer solution of $0.0005 \mathrm{M}$ sodium dodecyl sulfate (SDS) and $0.0005 \mathrm{M}$ sodium oleate in $0.05 \mathrm{M} \mathrm{NaCl}$ was created for the mixed film experiments. Sodium oleate is known to be soluble in water up to $\sim 0.1 \mathrm{M}$, and reported values of its critical micelle concentration $(\mathrm{cmc})$ in water range from $\sim 0.001$ to $0.01 \mathrm{M} .{ }^{57,58}$ Particles used in calibration experiments were generated as follows: Pure azelaic acid and oleic acid particles were generated via homogeneous nucleation following Thornton et al. ${ }^{59}$ Particles containing $\mathrm{NaCl}$ and nonanoic acid were generated by atomizing a saturated solution of nonanoic acid and $0.05 \mathrm{M} \mathrm{NaCl}$.

SEM-EDAX elemental analysis of single particles generated by atomizing $\mathrm{NaCl}$ solutions containing SDS or sodium oleate was performed. Particles emitted by the atomizer were dried using excess dry $\mathrm{N}_{2}$ and impacted on a $1.27 \mathrm{~cm}$ aluminum specimen mount (Ted Pella) using a custom-built low-pressuredrop impactor with a $\mathrm{d}_{50}$ cut-point of $\sim 300 \mathrm{~nm}$ (near the maximum in the surface area distribution). An FEI Sirion scanning electron microsope (SEM) with an energy dispersed spectrometer system (EDAX), and magnification of $20000 \times$, was used, with $5 \mathrm{kV}$ or $10 \mathrm{kV}$ acceleration. For every particle examined, peaks for $\mathrm{C}, \mathrm{O}, \mathrm{Na}, \mathrm{Cl}$, and $\mathrm{S}$ (when SDS was present) were observed, with $\mathrm{Na}$ and $\mathrm{Cl}$ dominating the mass fraction, suggesting that the particle population was internally mixed. For the oleate-containing particles, on average, the ratio of $\mathrm{Cl} / \mathrm{C}$ mass fractions was $17 \pm 13$ during a measurement at a particular location in the horizontal (compared to 21.5 in the atomizer solution), and for the SDS-containing particles, the $\mathrm{Cl} / \mathrm{C}$ mass ratio was $12 \pm 7$ (compared to 10.8 in the atomizer solution). The samples consisted of multiple layers of particles; therefore, it is difficult to be more quantitative, but we cannot rule out that the atomization process led to an enhancement of the organic material in the aerosol phase relative to its concentration in the atomizer.

The aerosol-laden flow from the atomizer $(\sim 1$ slpm $)$ was mixed with a $\sim 4$ slpm humidified $\mathrm{N}_{2}$ flow and transported $(\sim 10$ s) to the kinetics flow tube or photochemical reactor. The $\mathrm{RH}$ of the equilibrated $\mathrm{N}_{2}$ /aerosol stream was monitored at the outlet of the reaction vessels with a commercial hygrometer (Vaisala). Reported values for $\mathrm{RH}$ are accurate to within $2 \%$. Experiments were performed at $62 \%-67 \% \mathrm{RH}$. The aerosol population was also continuously sampled at the outlets of the reaction vessels by a differential mobility analyzer (DMA) coupled to an ultrafine condensation particle counter (CPC). The DMA/CPC drew humidified bulk flow for $\sim 1 \mathrm{~h}$ prior to starting experiments in order to equilibrate the RH of DMA sheath flow with the sample flow. The aerosols exhibited log-normal size distributions with a typical geometric standard deviation of 2.0. The $\mathrm{Na}_{2} \mathrm{SO}_{4} /$ sodium oleate aerosols had a surface area weighted mean radius, $r_{p}$, of $109 \pm 18 \mathrm{~nm}$, while for the $\mathrm{NaCl} /$ sodium oleate aerosols, $r_{p}=136 \pm 13 \mathrm{~nm}$. Total aerosol surface area was typically $10^{-3} \mathrm{~cm}^{2} \mathrm{~cm}^{-3}$.

When the saturated atomizer output combines with the drier bulk flow, water evaporates, causing the aerosols to become concentrated relative to the bulk atomizer solution. For example, at $62 \% \mathrm{RH}$, an aqueous $\mathrm{Na}_{2} \mathrm{SO}_{4}$ aerosol will contain $10.6 \mathrm{M}$ $\mathrm{Na}_{2} \mathrm{SO}_{4}$, and an aqueous $\mathrm{NaCl}$ aerosol will contain $8.6 \mathrm{M}$ $\mathrm{NaCl} .{ }^{60,61} \mathrm{We}$ believe the 10 -second transit time to the reactor at the experimental $\mathrm{RH}$ is sufficient for the aerosol particles to approach their equilibrium size and composition. Assuming the same proportional increase in concentration $(176 \times)$, and a homogeneous atomizer solution, we estimate that $0.001 \mathrm{M}$ sodium oleate in the atomizer solution corresponds to $0.176 \mathrm{M}$ sodium oleate in the aerosol. On the basis of a surface area 
weighted mean volume of $1.5 \times 10^{-17} \mathrm{~L}, 0.176 \mathrm{M}$ sodium oleate would correspond to an average of $1.6 \times 10^{6}$ sodium oleate molecules per particle. To avoid confusion concerning bulksurface partitioning of oleate and the total amount of oleate available per particle, we will refer to oleate concentration as a solute mass fraction (wt\%), instead of molarity and continue assuming that composition is approximately uniform across the aerosol population. This latter assumption is largely supported by the SEM-EDAX analysis and results discussed later. Thus, atomizing a solution containing $0.001 \mathrm{M}$ sodium oleate and 0.05 $\mathrm{M} \mathrm{Na}_{2} \mathrm{SO}_{4}$ yielded aerosols at $62 \% \mathrm{RH}$ that were $\sim 3.2 \mathrm{wt} \%$ oleate. It is possible that the aqueous particles become slightly acidic during transport through the tubing and reactors, which have been exposed to trace levels of $\mathrm{HNO}_{3}$ and $\mathrm{HCl}$, from many experiments in addition to these reported here. But, given the available aerosol volumes and reasonable estimates of acid backgrounds from the CIMS, we feel the $\mathrm{pH}$ of the particles is likely greater than 5 implying that there is a mixture of oleic acid and oleate. We continue to refer to the aqueous system as oleate with this caveat and note that in the atmosphere fatty acids in aqueous solutions will be mixtures of dissociated and undissociated acid.

Synthesis and Delivery of Gas-Phase Reactants. $\mathrm{O}_{3}$ was generated online during experiments by flowing 5-80 sccm of $\mathrm{O}_{2}$ with a carrier gas of $500 \mathrm{sccm} \mathrm{N}_{2}$ through a photocell containing a $\mathrm{Hg}$ pen-ray lamp (UVP) operating at $185 \mathrm{~nm} . \mathrm{O}_{3}$ concentration immediately downstream of the photocell was monitored using a UV absorption cell equipped with another $\mathrm{Hg}$ pen-ray lamp (Jelight) coated to primarily emit $254 \mathrm{~nm}$, a $254 \mathrm{~nm}$ interference filter, and a photodiode (Thorlabs).

$\mathrm{HONO}$ was generated for use as an $\mathrm{OH}$ source by flowing dry $\mathrm{N}_{2}$ over an acidified, stirred solution of $0.001 \mathrm{M}$ sodium nitrite $\left(\mathrm{NaNO}_{2}\right)$ in deionized water. ${ }^{62}$ This method produces both $\mathrm{HONO}$ and $\mathrm{NO}_{2}$, so we can only estimate an upper limit for the initial HONO concentration based on the predicted vapor pressure over the solution (20 ppm).

$\mathrm{N}_{2} \mathrm{O}_{5}$ was synthesized, stored, and delivered as in McNeill et al. ${ }^{25} \mathrm{NO}_{3}$ exists in equilibrium with $\mathrm{N}_{2} \mathrm{O}_{5}$ according to:

$$
\mathrm{N}_{2} \mathrm{O}_{5} \leftrightarrow \mathrm{NO}_{2}+\mathrm{NO}_{3}
$$

where $K_{1}=4.2 \times 10^{-11} \mathrm{~cm}^{3} \mathrm{molec}^{-1}$ at $21^{\circ} \mathrm{C} .{ }^{63}$ Typical initial concentrations in the flow reactor during the $\mathrm{N}_{2} \mathrm{O}_{5}$ uptake experiments were $\sim 5 \times 10^{11}$ molec cm ${ }^{-3}(20 \mathrm{ppb}) \mathrm{N}_{2} \mathrm{O}_{5}$ and $\sim 1 \times 10^{11}$ molec cm ${ }^{-3} \mathrm{NO}_{3}$. Both $\mathrm{NO}_{3}$ and $\mathrm{N}_{2} \mathrm{O}_{5}$ are detected as $\mathrm{NO}_{3}{ }^{-}$in our CIMS detection scheme. $\mathrm{NO}_{3}$ was obtained by allowing $\mathrm{N}_{2} \mathrm{O}_{5}$ to thermally decompose prior to injection into the reactor. $\mathrm{NO}_{3}$ concentrations in the flow tube during $\mathrm{NO}_{3}$ oxidation experiments ranged from 3 to $100 \mathrm{ppb}$.

Flow Reactors. $\mathrm{N}_{2} \mathrm{O}_{5}$ uptake kinetics were measured as in McNeill et al. ${ }^{25}$ Ozone oxidation experiments were carried out in a horizontally oriented, $7.5 \mathrm{~cm}$ o.d. Pyrex flow tube, $50 \mathrm{~cm}$ in length. The RH-equilibrated aerosol stream was introduced at one end of the flow tube through a perpendicular sidearm. The $\mathrm{O}_{3} / \mathrm{N}_{2}$ flow was introduced to the aerosol flow tube through a moveable injector consisting of a $6 \mathrm{~mm}$ o.d. stainless steel tube. After dilution, the $\mathrm{O}_{3}$ concentration in the aerosol flow tube varied from 0.3 to $6 \mathrm{ppm}$. The injector position was changed to vary reaction time and thus obtain kinetic information. All experiments were performed at ambient temperature $\left(\sim 21{ }^{\circ} \mathrm{C}\right)$ and pressure (760 Torr). $\mathrm{RH}$ and the aerosol size distribution were monitored at the outlet of the flow tube.

The flow velocity through the reactor, diffusion tube, and heated inlet was maintained by a critical orifice at the entrance to the low-pressure CIMS region, downstream of the heated inlet. The total flow through the reactor was 1.3 or $2.3 \mathrm{slpm}$, resulting in a flow velocity of 0.5 or $0.9 \mathrm{~cm} \mathrm{~s}^{-1}$. To study kinetics under well-mixed, fully developed laminar flow conditions, experiments were limited to the region between 15 and $35 \mathrm{~cm}$. To quench the reaction and protect a mechanical pump at the CIMS, the flow tube effluent was passed through a diffusion tube (TSI) filled with $\mathrm{O}_{3}$-scrubbing catalyst (Carus Chemical Company) after leaving the flow tube and before entering the heated inlet. This catalyst absorbs significant amounts of water vapor, effectively acting as a diffusion drier as well as an $\mathrm{O}_{3}$ scrubber. The $\mathrm{RH}$ at the output of the scrubber was typically $\ll 40 \%$, likely leading to the crystallization of salts in the aerosol particles. ${ }^{64}$ Crystallization after the reaction has been quenched has little impact on our conclusions about the kinetics. Crystallization prior to volatilization provides a measure of the partitioning of semivolatile organics to crystalline salt particles. But, we refrain from a strong quantitative assessment of gas-particle partitioning at this time because it is possible that gas-phase oxidation products were taken up by the $\mathrm{O}_{3}$ scrubber.

$\mathrm{OH}$ photoxidation experiments were carried out by flowing the RH-equilibrated aerosol stream along with a dilute HONO or $\mathrm{O}_{3}$ stream through a quartz photocell $25 \mathrm{~cm}$ long and $5 \mathrm{~cm}$ in diameter with a $1 \mathrm{~cm}$ inner sleeve containing an ozone-free $\mathrm{Hg}$ pen-ray lamp (Jelight, $254 \mathrm{~nm}$ ). Aerosols and $\mathrm{OH}$ precursors were mixed in a T-type fitting at the entrance to the photocell. When HONO was used as a precursor, $\mathrm{OH}$ was generated according to:

$$
\mathrm{HONO}+\mathrm{h} v \rightarrow \mathrm{OH}+\mathrm{NO}
$$

When $\mathrm{O}_{3}$ was the precursor, $\mathrm{OH}$ was formed from the reaction of excited oxygen with water:

$$
\begin{gathered}
\mathrm{O}_{3}+\mathrm{h} v \rightarrow \mathrm{O}\left({ }^{1} \mathrm{D}\right)+\mathrm{O}_{2} \\
\mathrm{O}\left({ }^{1} \mathrm{D}\right)+\mathrm{H}_{2} \mathrm{O} \rightarrow 2 \mathrm{OH}
\end{gathered}
$$

The initial concentration of HONO in the photocell was $\sim 20$ $\mathrm{ppb}$, whereas that of $\mathrm{O}_{3}$ was $\sim 4 \mathrm{ppm}$.

$\mathrm{OH}$ experiments consisted of establishing a baseline oleic acid signal for unreacted aerosol, acquiring a baseline mass spectrum for the aerosol in the presence of the $\mathrm{OH}$ precursors but in the absence of UV light, and then turning the lamp on and obtaining mass spectra. Kinetic information was obtained by varying the flow rate through the photocell. Total flow rate varied from 1.0 to $2.3 \mathrm{slpm}$, corresponding to a residence time in the photocell of $12-30 \mathrm{~s}$. RH and the aerosol size distribution were monitored at the outlet of the photocell. When $\mathrm{O}_{3}$ was used for $\mathrm{OH}$ generation, the flow tube effluent was passed through the $\mathrm{O}_{3}$-scrubbing diffusion tube after leaving the flow tube and before entering the heated inlet.

The resulting time-dependent gas-phase concentrations of $\mathrm{OH}$ and other photochemical byproducts were calculated using a box model which incorporates 48 reactions and uses rate data, absorption cross sections, and quantum yields given in DeMore et al. ${ }^{63} \mathrm{HONO}$ absorption into the aqueous aerosols is expected to be negligible due to their high ionic content. ${ }^{65}$ On the basis of the model, we estimate that the $\mathrm{OH}$ concentration in the photoreactor was $\sim 4 \times 10^{8}$ molecules $\mathrm{cm}^{-3}$. In the case of $\mathrm{OH}$ generation by $\mathrm{HONO}, \mathrm{HONO}$ was the dominant $\mathrm{OH}$ sink in the system and thus the $\mathrm{OH}$ concentration was largely independent of the actual HONO concentration.

CIMS Detection of Reactants and Products. A major difference between the experimental setup used in this study 


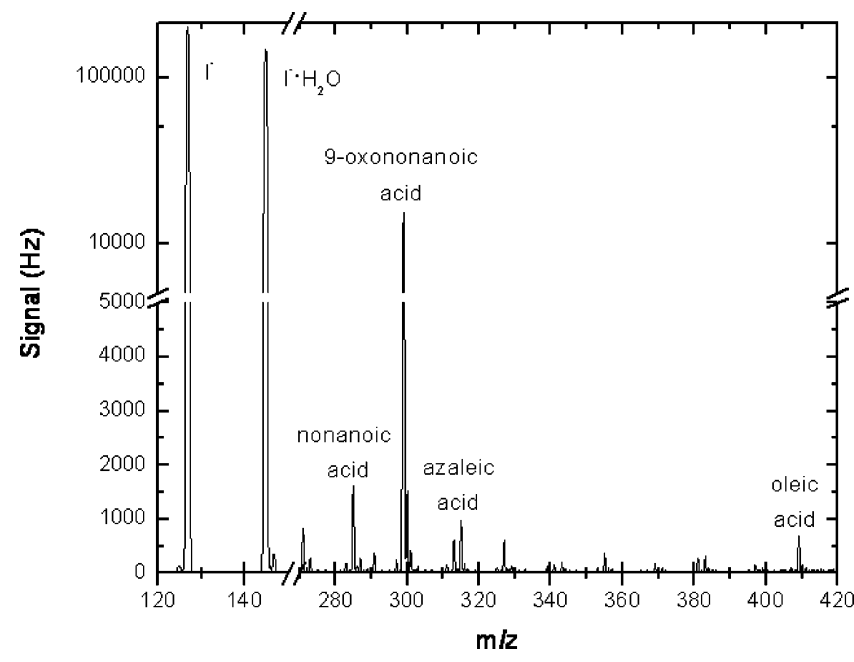

Figure 1. Mass spectrum of oleate ozone oxidation products obtained via CIMS using $\mathrm{I}^{-}$as reagent ion. Mass spectrometer signal is shown as a function of mass-to-charge ratio. Organic acids are detected as their clusters with $\mathrm{I}^{-}$.

and those used previously ${ }^{25,59}$ was that we employed a heated inlet upstream of the critical orifice and chemical ionization region for volatilization of particle phase organics in a manner similar, but not identical to, that described by Hearn and Smith. ${ }^{37,66}$ The inlet consisted of a $23 \mathrm{~cm}, 1.27 \mathrm{~cm}$ OD PFA tube wrapped with heating tape (VWR). Inlet temperature was monitored and controlled using a thermocouple and temperature controller (Omega). A heat transfer model was used to infer the temperature of the gas and particle stream from the measured external temperature. At $150{ }^{\circ} \mathrm{C}$, an offset of 10 to $20^{\circ} \mathrm{C}$ exists between the measured external temperature and the exit temperature of the gas inside, for flow rates between 1 and 2 slpm. Results presented in this paper are reported in terms of the mean internal gas temperature in the heated region rather than the exit temperature.

$\mathrm{N}_{2} \mathrm{O}_{5}, \mathrm{NO}_{3}$, oleate (detected as oleic acid), and the oxidation products were detected via CIMS using $\mathrm{I}^{-}$as the reagent ion. $\mathrm{I}^{-}$was generated by flowing trace amounts of $\mathrm{CH}_{3} \mathrm{I}$ in $1-2$ slpm $\mathrm{N}_{2}$ through a ${ }^{210} \mathrm{Po}$ ionizer (NRD) into the chemical ionization region, which consists of a $3.8 \mathrm{~cm}$ OD stainless steel tube manifold. The ionizer was positioned perpendicular to this manifold, with the effluent $\mathrm{N}_{2} / \mathrm{I}^{-}$flow entering the chemical ionization region through a port $\sim 5 \mathrm{~cm}$ away from the mass spectrometer front aperture. The pressure in the CIMS region was $\sim 60$ Torr, yielding an ion-neutral reaction time of $\sim 20$ ms. $\mathrm{N}_{2} \mathrm{O}_{5}$ and $\mathrm{NO}_{3}$ were monitored as $\mathrm{NO}_{3}{ }^{-}(62 \mathrm{amu})$, with a sensitivity of $1.6 \mathrm{~Hz} \mathrm{ppt}^{-1}$ at $50 \% \mathrm{RH}$.

Oleate was monitored as the cluster of oleic acid with $\mathrm{I}^{-}$, $\mathrm{I}^{-} \cdot \mathrm{C}_{18} \mathrm{H}_{34} \mathrm{O}_{2}$ (409 amu), with a sensitivity of $\sim 1 \mathrm{~Hz} \mathrm{ppt}^{-1}$. Oxidation products were also detected as clusters with $\mathrm{I}^{-}$. Therefore, when monitoring particle composition, the electric field inside the collisional dissociation chamber (CDC) was reduced to minimize declustering. With the heated inlet upstream of the CIMS, we observed a step increase in oleic acid signal $\sim 30 \mathrm{~s}$ after turning on the aerosol flow. The delay is roughly equal to the residence time calculated for the flow system, and the step-like increase is indicative of rapid response. The response of the oleic signal to varying the mass concentration of mixed oleate/salt particles used throughout the study was linear. A representative figure is available in the Supporting Information.

Figure 1 is a representative mass spectrum obtained during an $\mathrm{O}_{3}$ oxidation experiment. Mass-to-charge ratios consistent
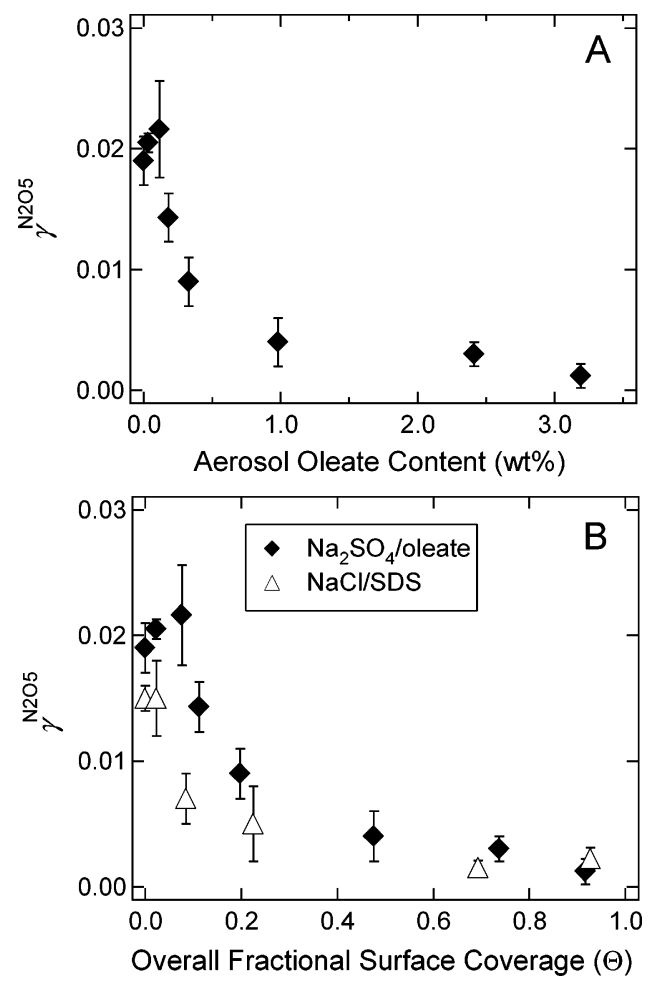

Figure 2. $\mathrm{N}_{2} \mathrm{O}_{5}$ uptake by aqueous aerosols containing varying amounts of oleate. Reaction probability, $\gamma^{\mathrm{N}_{2} \mathrm{O}_{5}}$, is plotted (a) versus oleate concentration in the aerosol and (b) as a function of overall fractional surface coverage in the aerosol population, assuming 1 monolayer $=$ $2 \times 10^{14} \mathrm{molec} \mathrm{cm}^{-2}$ (see text for details). Data shown is for $\sim 20 \mathrm{ppb}$ $\mathrm{N}_{2} \mathrm{O}_{5}$ reacting with sodium oleate-doped $\mathrm{Na}_{2} \mathrm{SO}_{4}$ aerosols at $62 \% \mathrm{RH}$. Data for reaction of SDS-doped $\mathrm{NaCl}$ aerosols at $60 \% \mathrm{RH}$ from McNeill et al. ${ }^{25}$ are also shown for comparison.

with nonanoic acid, 9-oxononanoic acid, azelaic acid, and oleic acid were detected. Calibration experiments performed for azelaic acid and nonanoic acid indicate that they are detected with a factor of $\sim 3$ higher sensitivity per molecule than oleic acid, perhaps due, in part, to the difference in mass (188 amu for azelaic acid vs 283 amu for oleic acid). By this argument, and from comparing relative signal changes, it is likely that 9-oxononanoic acid is also detected with higher sensitivity than oleic acid, and that it is present in higher abundance than the other products. This notion is consistent with the observations of other investigators. ${ }^{37,39,43,46}$ At this time we cannot rule out other species contributing to the observed signal. Sensitivity to pure oleic acid was $\sim 2 \times$ that for oleate in the aqueous particles.

\section{Results and Discussion}

$\mathrm{N}_{2} \mathrm{O}_{5}$ Uptake and Inferred Aerosol Mixing State. We studied the interaction of $\mathrm{N}_{2} \mathrm{O}_{5}$ with the aqueous oleate-doped aerosols to probe the surface state of the droplets. A significant body of evidence suggests that $\mathrm{N}_{2} \mathrm{O}_{5}$ reactive uptake rates are sensitive to the presence of organics at the aerosol surface. ${ }^{23,25,67-69}$ First-order rate coefficients for $\mathrm{N}_{2} \mathrm{O}_{5}$ loss, $k^{I}$, were determined from the slopes of measured $\mathrm{N}_{2} \mathrm{O}_{5}$ decay curves (see Supporting Information). The reactive uptake coefficient, $\gamma^{\mathrm{N}_{2} \mathrm{O}_{5}}$, for each experiment was calculated from $k^{I}$ as described in McNeill et al. ${ }^{25}$ Figure $2 \mathrm{a}$ shows $\gamma^{\mathrm{N}_{2} \mathrm{O}_{5}}$ as a function of oleate content in the aerosol. When less than 0.05 wt $\%$ oleate was present, no effect was observed, i.e., $\gamma^{\mathrm{N}_{2} \mathrm{O}_{5}}$ was the same as when no surfactant was present. Signs of $\mathrm{N}_{2} \mathrm{O}_{5}$ uptake supression began at 0.08 wt $\%$ oleate, and $\gamma^{\mathrm{N}_{2} \mathrm{O}_{5}}$ decreased further with increasing oleate concentration until $3.2 \mathrm{wt} \%$, where $\gamma^{\mathrm{N}_{2} \mathrm{O}_{5}}=0.001 \pm$ 0.001 . This behavior is analogous to what we observed with 
SDS, ${ }^{25}$ another soluble surfactant, and is suggestive of an organic monolayer forming at the gas-aerosol interface. That is, the quantity $1-\gamma^{\mathrm{N}_{2} \mathrm{O}_{5}}$ appears qualitatively like a surface adsorption isotherm for oleate.

Following McNeill et al., ${ }^{25}$ we take 3.2 wt $\%$ oleate as the concentration at which "full surface coverage" is reached because $\gamma^{\mathrm{N}_{2} \mathrm{O}_{5}}$ plateaus at that point. Distributing that amount of oleate over the surface of a $150 \mathrm{~nm}$ radius particle, we infer an oleate footprint of $50 \AA^{2}$, which is consistent with the literature value for oleic acid in surface films $48 \AA^{2} .{ }^{70}$ This agreement would be a remarkable coincidence if oleate were unevenly distributed across the particle population to a significant degree, and implies that oleate partitions to the surface of most particles. The polydisperse nature of our particle population means that the actual surface coverage of an individual particle is a function of its size even if oleate is uniformly distributed in a constant ratio to $\mathrm{NaCl}$ or $\mathrm{Na}_{2} \mathrm{SO}_{4}$, because there is a distribution of surface area-to-volume ratios. We can estimate the fraction of the total available surface area of our polydisperse aerosol population that is occupied by oleate according to:

$$
\Theta=\frac{\sum_{i} \theta_{i} N_{i}}{\sum_{i} N_{i}}
$$

where $\theta_{i}$ is fractional surface coverage of the aerosol in the DMA size bin $i$ and $N_{i}$ is the number density in bin $i .^{25}$ The coverage in a specific size bin, $\theta_{i}$, is determined by using the established footprint of oleic acid in surface films of $48 \AA$, which corresponds to $2 \times 10^{14}$ molec $\mathrm{cm}^{-2}$ for complete monolayer coverage. Under the assumptions that oleate is distributed across the aerosol population in a constant ratio to $\mathrm{NaCl}$ or $\mathrm{Na}_{2} \mathrm{SO}_{4}$, and that all oleate in the particle partitions to the surface until a saturation surface coverage is reached, we calculate $\Theta \approx 0.9$ (90\% overall surface coverage) for a typical aerosol population used in the oxidation studies. Implicit in this formulation is the idea that, at $\Theta \approx 0.9$, there are smaller particles (i.e., with larger surface area-to-volume ratios) that do not have sufficient oleate to cover the surface. We also assume that the small fraction of large particles containing more oleate than can be accommodated at the surface still have a complete surface coverage.

Figure $2 \mathrm{~b}$ shows the data from Figure $2 \mathrm{a}$ plotted as a function of overall fractional oleate surface coverage, $\Theta$, calculated for each point according to eq 4. Data from McNeill et al. for $\mathrm{N}_{2} \mathrm{O}_{5}$ uptake at $60 \% \mathrm{RH}$ to $\mathrm{NaCl}$ particles containing SDS are shown for comparison. ${ }^{25}$ For a given oleate concentration, the standard deviation of $\Theta$ due to variation in the particle size distributions between decays was found to be less than $5 \%$ of the $\Theta$ value. The similar effect of SDS and oleate on $\gamma^{\mathrm{N}_{2} \mathrm{O}_{5}}$ is not unexpected, given their similar footprints and that both form expanded films. ${ }^{71,72}$

For an aerosol $\mathrm{pH} \leq 7$ at room temperature, micelles are not expected to form in the bulk but other aggregates are possible. ${ }^{19}$ Given the predicted composition of the aerosol particles used in the oxidation experiments (3.2 wt \%) and their high surface area-to-volume ratio, assuming that oleate ions partition to the gas-aerosol interface results in essentially no monomer remaining in the aerosol bulk for a particle with the surface area weighted mean radius. The phase behavior of many surfactants is dependent on ionic strength and, to our knowledge, has not been determined for sodium oleate in an aqueous system that is supersaturated in $\mathrm{NaCl}$ or $\mathrm{Na}_{2} \mathrm{SO}_{4}$. However, our experimental results show no evidence of micelle or aggregate formation in

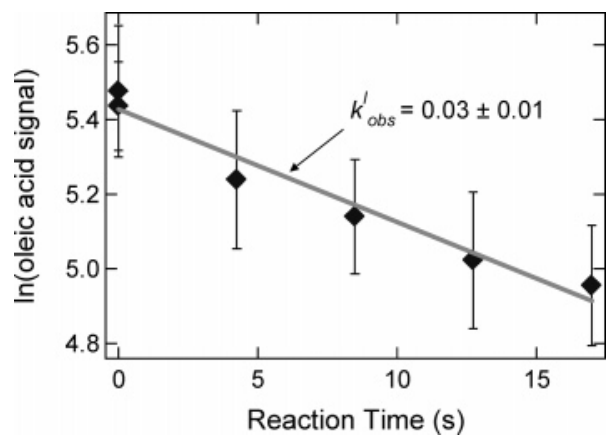

Figure 3. Representative oleic acid signal decay for oxidation of aqueous $\mathrm{NaCl}$ aerosol containing 3.2 solute wt\% oleate by 2 ppm $\mathrm{O}_{3}$. The natural logarithm of the signal at 409 amu is plotted versus the reaction time, which is a function of injector position in the flow tube. The error bars represent the standard deviation in the raw data used in the average. The line is the result of a weighted linear least-squares fit to the decay curve.

the atomizer leading to a nonuniform distribution of oleate in the aerosol population. The results of the SEM-EDAX analyisis, which showed that the particles were internal mixtures consisting mostly of inorganics, together with the $\mathrm{N}_{2} \mathrm{O}_{5}$ uptake behavior and our observation that the oxidation of oleate in our aerosols follows a Langmuir-Hinshelwood dependence on $\mathrm{O}_{3}$ (see below) all point to oleate partitioning to the gas-aerosol interface in a manner that is similar to what we observed in our previous work with SDS. ${ }^{25}$ That said, the composition of our particles is likely more complex than that of a monodisperse population of uniformly coated particles and more detailed experiments probing size dependence are warranted.

$\mathrm{NO}_{3}$ Oxidation. We investigated processing of oleate by $\mathrm{NO}_{3}$ using the aerosol CIMS technique to monitor oleate in the presence of $\mathrm{NO}_{3} / \mathrm{N}_{2} \mathrm{O}_{5}$. We did not observe a measurable decay in oleic acid signal on the timescales of our experiments for up to $100 \mathrm{ppb} \mathrm{NO}_{3}$. Thus, $\gamma^{\mathrm{NO}_{3}}<10^{-3}$ is a conservative upper limit to the reaction probability for $\mathrm{NO}_{3}$ loss to oleate in our particles. This result is generally consistent with what was observed by Knopf et al. on saturated organic SAMs ${ }^{73}$ and by Moise and Rudich ${ }^{74}$ on bulk unsaturated and saturated organic films. Docherty and Ziemann observed oligomeric organonitrate products upon exposure of pure liquid oleic acid particles to $\sim 80 \mathrm{ppb} \mathrm{NO}_{3}$ in an environmental chamber, indicating that a reaction certainly occurs. ${ }^{75}$

Ozone Oxidation Kinetics and Mechanism. In the presence of $\mathrm{O}_{3}$, we observed a decrease in oleic acid signal along with a concomitant increase in the nonanoic acid, 9-oxononanoic acid, and azelaic acid product signals. The injector position was changed relative to the flow tube exit to obtain the decay in oleic acid signal as a function of reaction time in the flow tube. Data from a representative decay experiment obtained at $2 \mathrm{ppm}$ $\mathrm{O}_{3}$ are shown in Figure 3. Oleic acid signal is plotted on a log scale as a function of the reaction time, which is proportional to the injector position in the flow tube (distance from the flow tube outlet). The error bars represent the standard deviation in the raw data used in the average. The linearity of the curve suggests first-order kinetics over the time scale investigated. Therefore, a pseudo-first-order rate coefficient for $\mathrm{O}_{3}$ loss, $k^{I}$, can be determined from the slope of a weighted linear leastsquares fit to the decay curve. Representative product growth curves for mass-to-charge ratios consistent with nonanoic acid, 9-oxononanoic acid, and azelaic acid are available in the Supporting Information.

The rate constants derived from a number of experiments with varying $\mathrm{O}_{3}$, aerosol substrate, and organic composition are 

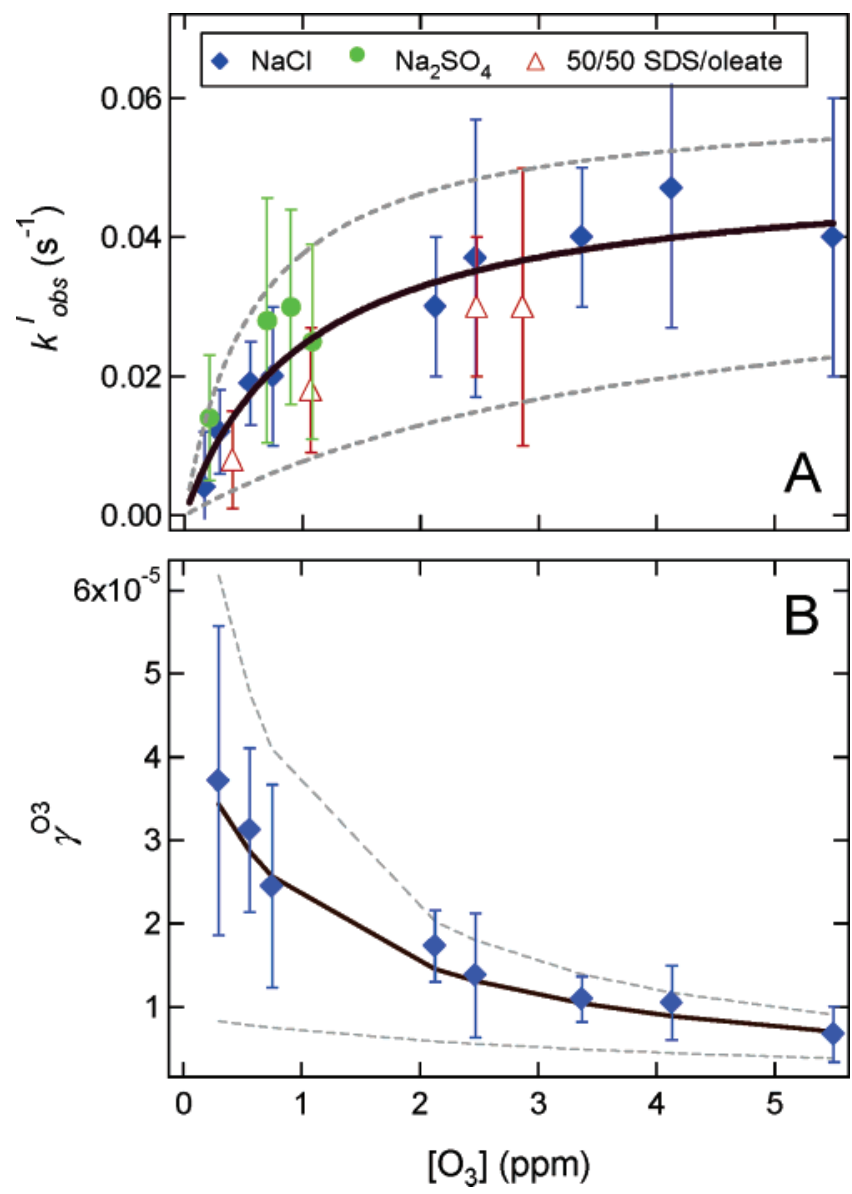

Figure 4. Reaction kinetics for $\mathrm{O}_{3}+$ oleate in surface films. Data are shown for the oxidation of aqueous $\mathrm{NaCl}(\bullet)$ and $\mathrm{Na}_{2} \mathrm{SO}_{4}(\bullet)$ aerosols containing 3.2 solute wt $\%$ oleate, and aqueous $\mathrm{NaCl}$ aerosols containing a 50/50 mixture of SDS and sodium oleate $(\triangle)$. (A) Pseudo-first-order rate coefficients. Measured pseudo-first-order rate coefficient, $k^{I}$ is shown as a function of $\left[\mathrm{O}_{3}\right]$. The best fit curve based on the LangmuirHinshelwood mechanism is shown (black line) along with the confidence intervals (dashed lines). (B) Reaction probability. Apparent reaction probability, $\gamma^{\mathrm{O}_{3}}$, calculated according to eq 6 , is shown as a function of $\left[\mathrm{O}_{3}\right]$. The curve based on the Langmuir-Hinshelwood mechanism are shown (black line) along with the confidence intervals (dashed lines).

plotted versus $\mathrm{O}_{3}$ concentration in Figure 4a. The measured rate constant increases with $\left[\mathrm{O}_{3}\right]$ at low $\mathrm{O}_{3}$ concentrations and reaches a plateau, becoming independent of further increases in $\left[\mathrm{O}_{3}\right]$. The lines fit to the data are based on a LangmuirHinshelwood model, in which the gas-phase reactant $\left(\mathrm{O}_{3}\right)$ must first adsorb to the surface according to a Langmuir isotherm before the reaction takes place. Other kinetic models that have been applied to ozone oxidation of pure oleic acid particles exhibit a linear dependence of $k^{I}$ on $\left[\mathrm{O}_{3}\right]$ and can be ruled out on this basis. ${ }^{39,40}$ The kinetic data for $\mathrm{Na}_{2} \mathrm{SO}_{4}$ aerosols and mixed SDS-oleate films are consistent with that observed for the oleate/ $\mathrm{NaCl}$ aqueous system (see Figure 4a), but not enough data is available to confirm Langmuir-Hinshelwood behavior for those systems.

Within the Langmuir-Hinshelwood framework, the pseudofirst-order rate coefficient may be parametrized as follows: ${ }^{76}$

$$
k^{\mathrm{I}}=\frac{k_{\max }^{\mathrm{I}} K_{\mathrm{O}_{3}}\left[\mathrm{O}_{3}\right]}{1+K_{\mathrm{O}_{3}}\left[\mathrm{O}_{3}\right]}
$$

where $k_{\max }^{\mathrm{I}}$ is the pseudo-first-order rate constant for a satu- rated surface, and $\mathrm{K}_{\mathrm{O}_{3}}$ is the equilibrium constant for $\mathrm{O}_{3}$ at the surface, representing a ratio of the adsorption/desorption rate constants coefficients involving both bulk phases. ${ }^{77}$ The bestfit Langmuir-Hinshelwood parameters achieved from a weighted nonlinear least-squares fit of eq 5 to the rate data in Figure $4 \mathrm{a}$ are $k_{\max }^{\mathrm{I}}=0.05 \pm 0.01 \mathrm{~s}^{-1}$ and $K_{\mathrm{O}_{3}}=4( \pm 3) \times 10^{-14}$ $\mathrm{cm}^{3}$ molec $^{-1}$. The best-fit curve is shown in Figure 4a (black line) along with the confidence intervals (dashed lines). Our value for $K_{\mathrm{O}_{3}}$ is greater than that observed for anthracene at the gas-liquid interface $\mathrm{e}^{78,79}$ and lies within the range of equilibrium adsorption constants reported for $\mathrm{PAH}$-coated solid systems: $10^{-15}<K_{\mathrm{O}_{3}}<10^{-13} \mathrm{~cm}^{3}$ molec $^{-1} \cdot 80,81$

$\mathrm{O}_{3}$ oxidation of unsaturated surface organics has been reported to follow a Langmuir-Hinshelwood mechanism for many systems. ${ }^{53,78-81}$ Most of these systems have been solid surfaces, although particularly relevant are the findings of Mmereki and Donaldson that ozone oxidation of anthracene at the gas-aqueous interface also follows this mechanism. ${ }^{78,79}$ To our knowledge, this is the first demonstration of Langmuir-Hinshelwood kinetics for mixed organic-inorganic submicron aqueous aerosols. If the oleate arranges predominantly in a monolayer film on an aqueous substrate, as our $\mathrm{N}_{2} \mathrm{O}_{5}$ kinetics suggest, then the "reactive surface" in our system would differ from a classical Langmuir surface in that (a) the reactive sites (the oleate double bonds) are in a liquid-like film on an aqueous surface, rather than on a solid surface, (b) $\mathrm{O}_{3}$ may diffuse through the film into the aqueous bulk of the particle, and out again, and (c) the surface to which $\mathrm{O}_{3}$ adsorbs might be changing over the course of an oxidation experiment. Figure 4 clearly shows that our observations are consistent with saturation of the reactive surface at high $\left[\mathrm{O}_{3}\right]$. We can rationalize the observed agreement with the Langmuir-Hinshelwood model as follows: A steady-state concentration of $\mathrm{O}_{3}$ develops in a surface layer due to the flux of $\mathrm{O}_{3}$ from the gas phase and into and out of the aqueous aerosol core. As the gas-phase $\mathrm{O}_{3}$ concentration increases, the steadystate concentration in the layer increases along with the oxidation rate. At a certain $\mathrm{O}_{3}$ concentration, the oxidation rate is no longer limited by the availability of $\mathrm{O}_{3}$ in the film but by the probability of reaction per double-bond encounter, resulting in the reaction rate being limited at high $\left[\mathrm{O}_{3}\right]$. The significant water flux in and out of the particle expected at $65 \% \mathrm{RH}$ may act to maintain an interface which is similar to $\mathrm{O}_{3}$ throughout the oxidation period. In addition, it may be that the change in the surface during oxidation is slow compared to the adsorption and desorption rates of $\mathrm{O}_{3}$.

Continuing to apply the Langmuir-Hinshelwood model to our system, we calculate the apparent reaction probability, $\gamma^{\mathrm{O}_{3}}$, following Ammann et al.: ${ }^{82}$

$$
\begin{aligned}
\gamma^{\mathrm{O}_{3}} & =\frac{4 k^{\mathrm{I}}}{\sigma \omega\left[\mathrm{O}_{3}\right]} \\
& =\frac{4 k_{\max }^{\mathrm{I}} K_{\mathrm{O}_{3}}}{\sigma \omega\left(1+K\left[\mathrm{O}_{3}\right]\right)}
\end{aligned}
$$

where $\omega$ is the molecular velocity of $\mathrm{O}_{3}$ and $\sigma$ is the oleic acid cross section $\left(5 \times 10^{-15} \mathrm{~cm}^{2}\right)$. In eq $6 \mathrm{a}, \gamma^{\mathrm{O}_{3}}$ is defined as the fraction of collisions between $\mathrm{O}_{3}$ gas molecules and oleate at the surface that result in reactive loss of oleate. If $k^{\mathrm{I}}$ were linearly dependent on the gas-phase $\mathrm{O}_{3}$ concentration, $\gamma^{\mathrm{O}_{3}}$ would be independent of $\left[\mathrm{O}_{3}\right]$. Equation $6 \mathrm{~b}$ modifies $6 \mathrm{a}$ to be in accord with the Langmuir-Hinshelwood mechanism, allowing a saturation phenomenon to be replicated. It is not necessary to correct for a reduction in collision rate as the surface oleate is 
depleted during reaction because we monitor the loss of the particle-phase reactant (oleate) in excess $\mathrm{O}_{3}$, and $\left[\mathrm{O}_{3}\right]$ can be assumed constant over the course of a decay. ${ }^{82}$

The reaction probability calculated using eq 6 a from the $\mathrm{NaCl} /$ sodium oleate aerosol data in Figure $4 \mathrm{a}$ is shown as a function of $\left[\mathrm{O}_{3}\right]$ in Figure $4 \mathrm{~b}$. Values of $\gamma^{\mathrm{O}_{3}}$ range from $10^{-5}$ at the highest $\left[\mathrm{O}_{3}\right]$ to $5 \times 10^{-5}$ at the lowest $\mathrm{O}_{3}$ levels. The best-fit Langmuir-Hinshelwood parameters based on the rate data in Figure $4 \mathrm{a}$ were used in eq $6 \mathrm{~b}$ to calculate the parametrization for $\gamma_{3}$, which is shown along with the confidence intervals in Figure $4 \mathrm{~b}$. The uptake coefficient exhibits a dependence on $\mathrm{O}_{3}$ that is again similar to other systems. ${ }^{53,78-81}$ However, our values of $\gamma^{\mathrm{O}_{3}}$ are more than a factor of 10 lower than those measured on bulk oleic acid film or droplet systems, ${ }^{37,38,40,48,50}$ and about a factor of 10 lower than that measured on terminal alkene selfassembled monolayers (TASAMs). ${ }^{49}$ On the basis of our inferred aerosol mixing state, there are three differences between this study and those performed on macroscopic or pure oleic acid aerosol systems and TASAMs: (1) the oleate $/ \mathrm{O}_{3}$ "reactive zone" on our aerosol particles is likely to be approximately a single molecule thick, (2) the double bond is not terminal, and (3) the film exists on an aqueous substrate. In a pure oleic acid aerosol or macroscopic film, $\mathrm{O}_{3}$ will encounter a double bond several times as it diffuses through the bulk, and thus, per collision with the surface, there are a greater number of chances for a reactive encounter. The reactive diffusive length, $l$, for ozone reacting in bulk oleic acid systems has been estimated to be 10 to $20 \mathrm{~nm} .{ }^{38,40}$ The reactive diffusive length is defined as

$$
l=\left(\frac{D_{l}}{k^{\mathrm{I}}}\right)^{1 / 2}
$$

where $k^{\mathrm{I}}$ is the pseudo-first-order reaction rate and $D_{l}$ is the diffusion coefficient for $\mathrm{O}_{3}$ in oleic acid. ${ }^{83} D_{l}$ has been estimated to be $10^{-5} \mathrm{~cm}^{2} \mathrm{~s}^{-1} .38$ Thus, for macroscopic oleic acid films and pure oleic acid particles, the reactive diffusive length is much smaller than the characteristic length of the system, $a$ (particle radius or coating thickness). The characteristic length of our oleate films, on the other hand, assuming monolayer coverage, is $\sim 1 \mathrm{~nm}$, which is much smaller than $l$. Given that an $\mathrm{O}_{3}$ molecule diffusing through the organic layer into the aqueous bulk could diffuse out, we can double this characteristic length to $a \approx 2 \mathrm{~nm}$. Drawing an analogy to a pure oleic acid droplet of $D_{p}=2 \mathrm{~nm}$, and using the correction proposed by Hanson et al., 83

$$
\gamma_{\text {surf }}^{\mathrm{O}_{3}}=\left[\operatorname{coth}\left(\frac{a}{l}\right)-\left(\frac{a}{l}\right)^{-1}\right] \gamma_{\text {bulk }}^{\mathrm{O}_{3}}
$$

we find that a correction factor of $0.03-0.07$ would apply if extrapolating bulk reactivity $\left(\gamma_{\text {bulk }}^{\mathrm{O}_{3}}\right)$ to that of a surface film $\left(\gamma_{\text {surf }}^{\mathrm{O}_{3}}\right)$. Assuming $\gamma_{\text {bulk }}^{\mathrm{O}_{3}}=10^{-3}$, we predict values of $\gamma_{\text {surf }}^{\mathrm{O}_{3}}$ between $3 \times 10^{-5}$ and $7 \times 10^{-5}$ - consistent with our observations. An underlying assumption of this analysis is that the properties of bulk oleic acid systems, such as $\mathrm{O}_{3}$ solubility, diffusivity, and reaction rate constants, are the same for an oleate surface layer. Katrib et al. ${ }^{46}$ studied the ozone oxidation of oleic acid films as thin as $2 \mathrm{~nm}$ on polystyrene beads but did not report kinetic information. Because the characteristic length for the thinnest films they studied was similar to that in our system, we predict similar values of $\gamma^{\mathrm{O}_{3}}$ assuming that the $\mathrm{RH}$ during the experiment was the same as ours.

The notion of a single molecule characteristic length for reaction in our system makes it similar in some respects to the TASAM systems studied by Moise and Rudich and Finlayson-
Pitts and co-workers, with the exception that our substrates are aqueous salt solutions. ${ }^{49,53,54}$ However, our measured reactive uptake coefficient was a factor of 10 lower than the measurements made on TASAMs by Moise and Rudich. ${ }^{49}$ One explanation for this difference may be that the oleate double bond lies in the center of the molecule and is therefore likely to be less accessible than in the TASAMs. Furthermore, the aqueous nature of our surface and high partial pressures of water may further inhibit the reaction.

To conclude this section, we note that a coating on atmospheric aerosol would likely be a mix of saturated and unsaturated surfactants. Depending on the aerosol age, some components would likely be oxygenated. Here we found that the ozonolysis of sodium oleate in a mixed film with SDS, a saturated alkyl surfactant, exhibited the same oxidation kinetics as a pure sodium oleate film. It is possible that a mixed film containing surfactants known to exhibit tight packing, such as stearic acid, would affect the kinetics of oleate oxidation differently. Wadia et al. observed $\gamma^{\mathrm{O}_{3}} \approx 3 \times 10^{-6}$ for $\mathrm{O}_{3}$ oxidation of OPPC, an organic phospholipid with moieties analogous to oleic acid and palmitic acid. ${ }^{84}$ The low value of $\gamma^{\mathrm{O}_{3}}$ observed by Wadia et al. may be due to the relative inaccessibility of the double bond. Experiments using macroscopic systems or aerosols composed of oleic and other fatty acids suggest that the presence of other organics affects oleic acid oxidation by altering the phase and morphology of the particles or bulk liquid film. ${ }^{43,45,52}$ Similarly, our results suggest that oxidation of an alkenoic double bond becomes slower as the overall aerosol composition becomes more complex (i.e., oxidation is apparently slower for mixed organic-inorganic aerosols than for pure oleic acid aerosols). However, no significant effect of introducing a second organic species, SDS, was observed. We note here that surface active organics in atmospheric aerosol particles are not limited to fatty acids. In the seawater system alone, much work remains in order to assess the effects of other possibilities such as amino acids, proteinaceous material, and polysaccharides.

OH Photoxidation. The primary goal of the $\mathrm{OH}$ photooxidation experiments was to qualitatively examine the interaction of our mixed organic-inorganic aerosols with another oxidant. In the presence of $\mathrm{HONO}$ or $\mathrm{O}_{3} / \mathrm{H}_{2} \mathrm{O}$, we observed a decrease in oleic acid signal when the $254 \mathrm{~nm}$ lamp was turned on. No loss of oleate was observed due to photolysis in the absence of $\mathrm{OH}$ precursors. Many products were observed in the presence of $\mathrm{OH}$, including several species that were volatile at $298 \mathrm{~K}$, in contrast to the $\mathrm{O}_{3}$ oxidation products. Most notable was the appearance of mass-to-charge ratios consistent with acetic and formic acids upon $\mathrm{OH}$ generation as well as the decrease in signals consistent with $\mathrm{O}_{3}$ oxidation products.

Figure 5 shows kinetic data for the oxidation of oleate in the mixed particles by $\sim 2 \times 10^{8}$ molec $\mathrm{cm}^{-3} \mathrm{OH}$. The natural logarithm of the oleic acid signal is plotted on a log scale as a function of the reaction time, which was varied by changing the flow rate through the photochemical reactor. The error bars represent the standard deviation in the raw data used in the average. The point at zero time represents the average change in oleic acid signal upon turning the lamp on in the absence of $\mathrm{OH}$ precursors. Data are shown for both methods of $\mathrm{OH}$ generation used: $\mathrm{HONO}$ photolysis (diamonds) and $\mathrm{O}_{3}+\mathrm{H}_{2} \mathrm{O}$ (square). The data in Figure 5 were simulated using our photochemical box model and several scenarios for $\mathrm{OH}$ heterogeneous reaction, accounting for gas-phase diffusion limitations to the particle and diffusion-limited wall loss within the reactor. Scenarios tested included: $\mathrm{OH}$ reaction with oleate 


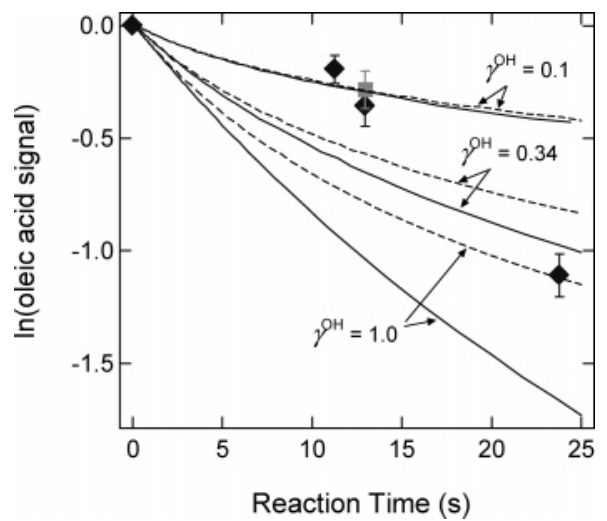

Figure 5. Reaction kinetics for $\mathrm{OH}$ oxidation of oleate in surface films. Results are shown for $\sim 4 \times 10^{8}$ molec $\mathrm{cm}^{-3} \mathrm{OH}$. Signal is plotted versus reaction time, which is a function of flow rate through the photolysis cell. The error bars represent the standard deviation in the raw data used in the average. Data are shown for $\mathrm{O}_{3}+\mathrm{H}_{2} \mathrm{O}$ (square) and $\mathrm{HONO}$ (diamonds) $\mathrm{OH}$ precursors. The lines represent photochemical box model simulations which include $\mathrm{OH}$ loss to oleate (solid) or $\mathrm{OH}$ loss to oleate and oleate products (dashed), with $0.1 \leq \gamma^{\mathrm{OH}} \leq 1$. See text for details.

only, $\mathrm{OH}$ reacting with a constant monolayer coverage of reactive organic material (to simulate $\mathrm{OH}$ reactions with both oleate and oxidation products), and varying precursor concentrations and particle radii. After examining the range of possibilities, we find that our experimental results are consistent with $0.1 \leq \gamma^{\mathrm{OH}} \leq 1$. Non-steady-state conditions and unknown mixing patterns within the photoreactor contribute uncertainty to this value. Efficient loss of $\mathrm{OH}$ to unsaturated organics at the aerosol surface is consistent with other studies of $\mathrm{OH}$ oxidation of surface organics, and this study represents an important extension in the sense that oxidation occurs in mixed aqueous organic/inorganic aerosols at ambient levels of humidity. ${ }^{26}$

Gas-Particle Partitioning of Oxidation Products. Our observation of volatile products after exposing the mixed particles to $\mathrm{OH}$ is consistent with Molina et al., who observed $\mathrm{OH}$-initiated volatilization of SAMs and solid organic surfaces. ${ }^{27}$ However, in our system, a number of unidentified products between 150 and 250 amu remained in the particle phase after the relatively short $\mathrm{OH}$ exposure times.

Although product yields were not a focus of the current study, our observations suggest that 9-oxononanoic acid was the most abundant ozone oxidation product. This is consistent with the mechanisms proposed by other investigators that include reaction of oleic acid with the Criegee biradical in pure oleic acid particles. ${ }^{37,39,43,46}$ The ozone oxidation products that we are able to observe using CIMS with $\mathrm{I}^{-}$as a reagent ion (nonanoic acid, 9-oxononanoic acid, and azelaic acid) were associated with the particle phase at ambient temperature. A temperature-programmed desorption experiment was performed to investigate the gas-particle partitioning of the ozone oxidation products. In this experiment, $\mathrm{O}_{3}$ oxidation was initialized with the heated inlet at room temperature, and then the temperature was slowly increased to $160{ }^{\circ} \mathrm{C}$, corresponding to $100{ }^{\circ} \mathrm{C}$ mean internal gas temperature in the heated region. Increasing the inlet temperature beyond this temperature did not result in an increase in the oleic acid or product signals. The results of the desorption experiment are shown in Figure 6. For each mass-to-charge ratio, any background signal that was present prior to initiating $\mathrm{O}_{3}$ oxidation was subtracted, and then the signal was normalized to the maximum value observed for that product. Temperatures shown are inferred from measured external inlet temperature

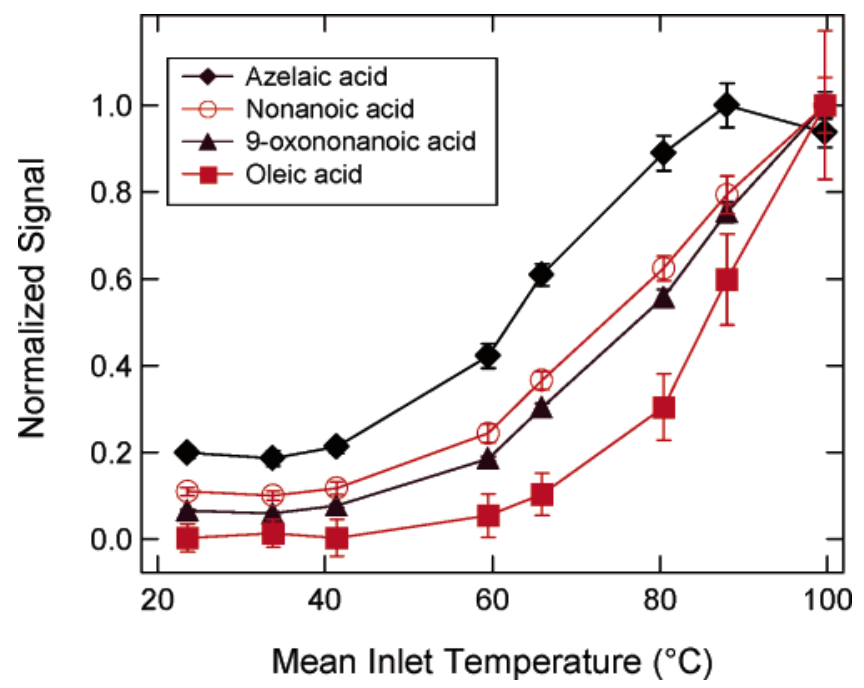

Figure 6. Temperature-programmed desorption study of $\mathrm{O}_{3}$ oxidation product volatility. Normalized mass spectrometer signal is shown for azelaic acid (diamonds), nonanoic acid (circles), 9-oxononanoic acid (triangles), and oleic acid (squares) as a function of mean heated inlet temperature. For each mass-to-charge ratio, any background signal present prior to initiating $\mathrm{O}_{3}$ oxidation was subtracted, and then the signal was normalized to the maximum value observed for that peak. The error bars represent the standard deviation in the raw data used in the average, also normalized to the maximum signal. For some points the error bars are smaller than the symbols. Mean inlet temperatures shown are inferred from the measured external inlet temperature using a heat transfer model.

using a heat transfer model. At least $90 \%$ of the nonanoic acid and 9-oxononanoic acid, $~ 80 \%$ of the azelaic acid, and $100 \%$ of the oleic acid molecules were observed to be in the particle phase at ambient temperature. The fact that we observe a nonnegligible signal for azelaic acid at room temperature points to a possible interference at that mass, since azelaic acid is less volatile than oleic acid in the pure state. ${ }^{85}$ This interference is present only after ozone oxidation of oleate.

To begin our discussion of the partitioning results, we note that we do not directly observe volatilization from aqueous particles. First, aqueous $\mathrm{NaCl}$ or $\mathrm{Na}_{2} \mathrm{SO}_{4}$ particles would crystallize in the heated region due to the significant decrease in relative humidity. Second, although we control the relative humidity in the aerosol kinetics flow tube to be $\sim 60 \%$, the ozone-scrubbing catalyst we use downstream of the flow tube absorbs water, such that the outlet stream is $\sim 10 \% \mathrm{RH}$, further ensuring that the aerosol particles are effectively dried before volatilization in the heated inlet. Thus, we infer products were partitioned to the aqueous particles because they were observed to be partitioned to the crystalline particles. Detection of volatilized products occurs $\sim 2 \mathrm{~s}$ after crystallization (and after more than $10 \mathrm{~s}$ of oxidation), which is on the order of the time required for gas - particle equilibrium to be established for nonanoic acid and our aerosol population, assuming unity mass accommodation and a gas-phase diffusion coefficient of $0.1 \mathrm{~cm}^{2}$ $\mathrm{s}^{-1}$. Because it is possible that gas-phase fractions of the semivolatile ozone oxidation products were taken up by the tubing walls and the $\mathrm{O}_{3}$ scrubbing catalyst, we refrain from quantitatively stating the fraction present in the gas and particle phases after oxidation.

Our partitioning results for the oleate $\mathrm{O}_{3}$ oxidation products in mixed aqueous salt particles are in qualitative agreement with those of Hearn and Smith $^{37}$ and Katrib et al., ${ }^{46}$ who observed that nonanoic acid, 9-oxononanoic acid, and azelaic acid are present in the condensed phase after ozone oxidation of pure 
oleic acid droplets or multilayer thick films of oleic acid. In aerosol generated from seed oil cooking, the gas-to-particle ratio of nonanoic acid was measured by Schauer et al. to be approximately 99:1 (partition coefficient $K_{\mathrm{p}} \approx 10^{-4}$ ). ${ }^{30}$ However, the same investigators found that aerosols generated by meat charbroiling exhibit what appears to be a nonequilibrium partitioning of volatile material to the particle phase, despite relatively long equilibration times. ${ }^{86}$ They suggest that this could be due to mass transfer limitations in the particles, which were expected to be solid.

To further explore our nonanoic acid partitioning observations, we performed additional gas-particle partitioning measurements using nonanoic acid/ $\mathrm{NaCl}$ aerosols. The nonanoic acid signal was insensitive to inlet temperature, indicating that nonanoic acid was present largely in the gas phase even after passing through the ozone scrubbing catalyst. This suggests that the additional organic content present in the oxidized oleatesalt particles enhances the partitioning of nonanoic acid. In support of this conclusion, even though nonanoic acid is sparingly soluble in water, ${ }^{85}$ a Henry's law analysis, accounting for the high ionic strength of the aqueous aerosols ${ }^{87}$ and acid dissociation at $\mathrm{pH} 7$, underestimates the observed partitioning of nonanoic acid to the aqueous particle phase by a factor of $\sim 10$.

Following Pankow, ${ }^{88}$ assuming nonanoic acid partitions to an organic subphase in the particle underestimates the signals from particle-bound nonanoic acid that we observe, unless the organic subphase is a nonideal mixture with an activity coefficient $<10^{-1}$, or an activity coefficient between 0.1 and 1 with the average molecular weight, $\langle\mathrm{MW}\rangle$, of the absorbing phase $<100$ amu. An $\langle\mathrm{MW}\rangle<100$ amu would imply significant amounts of water in the absorbing phase. ${ }^{89}$ Due to the compounded uncertainty in the parameters used as inputs for gas-aerosol partitioning calculations such as this one, applying this model to our system requires caution. Below we explore some possible interpretations of the disagreement between our observations and the partitioning model.

The discrepancy between the equilibrium partitioning model, which assumes solution ideality, and our observed particulate nonanoic acid can be explained by several possibilities, including: (1) organic oligomer formation by oleate oxidation products, (2) aggregate formation in the aqueous phase by fatty acids, and (3) mass transfer limitations due to the surface film. High-molecular-weight oligomers have been detected upon oleic acid ozonolyis; ${ }^{41,42,53-55}$ perhaps nonanoic acid is a monomer unit in such oligomers and is released during the $0.5 \mathrm{~s}$ of heating in the presence of water vapor that precedes detection. At sufficiently high concentrations, fatty acids under neutral to acidic conditions form oil or lamellar phases, or crystals depending on temperature and $\mathrm{pH} .{ }^{19}$ Aggregate formation by surface active material may result in scavenging of aerosol organics from the surface. ${ }^{90}$ It is possible that such a phenomenon would result in enhanced partitioning to the particle phase. Both of these cases would be accounted for in the partitioning model as an activity coefficient less than 1. Additionally, it is known that the presence of a surface organic film slows mass transport between the gas and aqueous phases. ${ }^{22-25}$ If an organic film does remain after oxidation, (a) the time required to achieve Henry's law equilibrium between the aqueous and gas phases will be extended, and (b) equilibrium between the aqueous and condensed organic subphases must be considered. It is also possible that other unidentified $\mathrm{O}_{3}$ oxidation products contribute to the signals we assume to be nonanoic acid, though we are unaware of any specific examples.
The heat of vaporization of organic species from particles is critical for predicting the temperature dependence of organic aerosol mass throughout the atmosphere. A Clausius-Clapeyron analysis $^{91}$ of the data in Figure 6 yields effective heats of vaporization of $43 \pm 5 \mathrm{~kJ} \mathrm{~mol}^{-1}$ for nonanoic acid and $\sim 70 \mathrm{~kJ}$ $\mathrm{mol}^{-1}$ for 9-oxononanoic and azelaic acids. These $\Delta H_{\mathrm{vap}}^{\mathrm{eff}}$ values are approximately $40 \%$ lower than $\Delta H_{\text {vap }}$ for the pure substances in this temperature range (note: no data is available for 9-oxononanoic acid). ${ }^{85}$ For oleic remaining in the film, we find $\Delta H_{\text {vap }}^{\text {eff }}=86 \pm 5 \mathrm{~kJ} \mathrm{~mol}^{-1}$, compared to $\sim 110 \mathrm{~kJ} \mathrm{~mol}^{-1}$ for pure oleic acid over this temperature range. ${ }^{85}$ We validated the temperature programmed desorption/Clausius-Clapeyron technique using pure palmitic acid aerosols and found that the observed $\Delta H_{\text {vap }}$ agreed with the literature value to within $7 \%$.

A reduction in apparent heat of vaporization over a mixture compared to the pure component $\Delta H_{\text {vap }}$ is to be expected. ${ }^{92}$ Similar inferences of reduced $\Delta H_{\text {vap }}^{\text {eff }}$ in mixed organic aerosols have been made. For the semivolatile ozonolysis products of $\alpha$-pinene, Donahue et al. and Offenberg et al. estimate $\Delta H_{\mathrm{vap}}^{\text {eff }}$ $\approx 30-44 \mathrm{~kJ} \mathrm{~mol}^{-1}$ from the temperature dependence of aerosol mass, whereas the typical single-component $\Delta H_{\text {vap }}$ of suspected products ranged from 100 to $120 \mathrm{~kJ} \mathrm{~mol}^{-1} .{ }^{93,94}$

Summary and Atmospheric Implications. The sum of our results implies that the oxidation of oleate present in submicron aqueous salt particles at $\sim 3.2 \mathrm{wt} \%$ occurs at the particle surface. To our knowledge, these data are the first to show that the ozone oxidation of oleate in aqueous aerosols follows LangmuirHinshelwood kinetics. This mechanism is in general agreement with previous observations of ozone oxidation of other surfacebound unsaturated organics. ${ }^{78,80,81} \mathrm{We}$ measure an apparent reactive uptake coefficient for $\mathrm{O}_{3}, \gamma^{\mathrm{O}_{3}}$, of $\sim 1 \times 10^{-5}$ to $6 \times$ $10^{-5}$, which can be reconciled with previous observations of $\gamma^{\mathrm{O}_{3}} \approx 10^{-3}$ in macroscopic or pure oleic acid aerosol systems ${ }^{37,38,40,48,50}$ by assuming a small characteristic length for reaction, as would be the case in a surface-based process. The oxidation of oleate in these particles by $\mathrm{OH}$ is very efficient, with our measurements suggesting an apparent reaction probability for $\mathrm{OH}$ and oleate between 0.1 and 1 . In contrast, we were unable to measure a loss of oleate in the presence of up to $100 \mathrm{ppb} \mathrm{NO}_{3}$ or $\mathrm{N}_{2} \mathrm{O}_{5}$ on the timescales of our experiment, suggesting $\gamma^{\mathrm{NO}_{3}}<0.001$, which is consistent with other studies. ${ }^{73,74}$ The low reactivity of $\mathrm{N}_{2} \mathrm{O}_{5}$ on mixed oleate-salt particles was also consistent with the formation of an oleate monolayer at the surface of most particles in our aerosol populations. This latter result lends support to a surface-based mechanism for ozone oxidation, the inefficient ozone oxidation due to a small characteristic length, and the efficient loss due to $\mathrm{OH}$.

The main atmospheric implication of our results is that the lifetime of unsaturated, surface active organics at the surface of aqueous aerosols would be $\sim 10$ min due to ozone oxidation under atmospheric conditions $\left(50 \mathrm{ppb} \mathrm{O}_{3}\right)$. Accounting for diffusion limitations, $\mathrm{OH}$ oxidation is a factor of $\sim 100$ slower if $\gamma^{\mathrm{OH}}=1$ and $[\mathrm{OH}] \approx 1 \times 10^{6}$ molec $\mathrm{cm}^{-3}$. In other studies, the ozone equilibrium adsorption constant, $K_{\mathrm{O}_{3}}$, has been observed to vary from $<10^{-16} \mathrm{~cm}^{3}$ molec ${ }^{-1}$ to $\sim 10^{-13} \mathrm{~cm}^{3} \mathrm{molec}^{-1}$ for PAH-coated solid $\mathrm{NaCl}$ and soot substrates, respectively, indicating that the underlying substrate can affect the reaction rate for unsaturated organics with ozone. ${ }^{80,81}$ If a similar trend exists for surface-adsorbed oleic acid, it could be one possible explanation for observations of oleic acid in aged ambient aerosol. Robinson et al. observed $80 \%$ oxidation of alkenoic acids, suggesting that $\gamma^{\mathrm{O}_{3}} \approx 10^{-6} \cdot{ }^{36}$ Allowing $K_{\mathrm{O}_{3}}$ in our system to vary from $10^{-16}$ to $10^{-13} \mathrm{~cm}^{3} \mathrm{molec}^{-1}$, at $50 \mathrm{ppb} \mathrm{O}_{3}, \gamma^{\mathrm{O}_{3}}$ for 
oleic acid at the gas-aerosol interface could vary from $10^{-7}$ to $10^{-4}$. This corresponds to a wide range of estimated lifetimes for an unsaturated organic molecule at the surface of a submicron aerosol particle, i.e., from minutes to days. Obviously, this suggestion requires experimental validation. The question remains as to whether surface active organics are likely to exist at the gas-aerosol interface in nature, affecting mass transfer, heterogeneous reactivity, and the gas-particle partitioning of other semivolatile organics.

Acknowledgment. This work was funded in large part by a grant from the Office of Earth Science (NIP/03-0000-0025) at the National Aeronautics and Space Administration (NASA). We thank Scot Martin and Arthur Goldsipe for useful discussions, and Greg Golden of the UW Nanotechnology User Facility for performing the SEM-EDAX analysis.

Supporting Information Available: Figures including a schematic of the experimental setup, the response of the 409 amu signal to varying the mass concentration of mixed oleate/ salt particles, representative $\mathrm{N}_{2} \mathrm{O}_{5}$ decays, and oleate $\mathrm{O}_{3}$ oxidation product growth curves. This material is available free of charge via the Internet at http://pubs.acs.org.

\section{References and Notes}

(1) Murphy, D. M.; Thomson, D. S.; Middlebrook, A. M. Geophys. Res. Lett. 1997, 24, 3197-3200.

(2) Murphy, D. M.; Thomson, D. S.; Mahoney, T. M. J. Science 1998 $282,1664-1669$

(3) Middlebrook, A. M.; Murphy, D. M.; Thomson, D. S. J. Geophys. Res.-Atmos. 1998, 103, 16475-16483.

(4) Buseck, P. R.; Posfai, M. Proc. Natl. Acad. Sci. U.S.A. 1999, 96 , $3372-3379$.

(5) Tervahattu, H.; Hartonen, K.; Kerminen, V. M.; Kupiainen, K.; Aarnio, P.; Koskentalo, T.; Tuck, A. F.; Vaida, V. J. Geophys. Res.-Atmos 2002, 107, 4319-4325.

(6) Russell, L. M.; Maria, S. F.; Myneni, S. C. B. Geophys. Res. Lett. 2002, 29, DOI: $10.1029 / 2002$ GL014874.

(7) Posfai, M.; Gelencser, A.; Simonics, R.; Arato, K.; Li, J.; Hobbs,

P. V.; Buseck, P. R. J. Geophys. Res.-Atmos. 2004, 109.

(8) Leck, C.; Bigg, E. K. Geophys. Res. Lett. 2005, 32.

(9) Leck, C.; Bigg, E. K. Tellus B 2005, 57, 305-316.

(10) Hinz, K. P.; Trimborn, A.; Weingartner, E.; Henning, S.; Baltensperger, U.; Spengler, B. J. Aerosol. Sci. 2005, 36, 123-145.

(11) Tervahattu, H.; Juhanoja, J.; Vaida, V.; Tuck, A. F.; Niemi, J. V.; Kupiainen, K.; Kulmala, M.; Vehkamaki, H. J. Geophys. Res.-Atmos. 2005 110, D06207, DOI: 10.1029/2004JD005400.

(12) Rogge, W. F.; Hildemann, L. M.; Mazurek, M. A.; Cass, G. R. Simonelt, B. R. T. Environ. Sci. Tech. 1991, 25, 1112-1125.

(13) O'Dowd, C. D.; Facchini, M. C.; Cavalli, F.; Ceburnis, D.; Mircea, M.; Decesari, S.; Fuzzi, S.; Yoon, Y. J.; Putaud, J. P. Nature 2004, 431, 676-680.

(14) Cavalli, F.; Facchini, M. C.; Decesari, S.; Mircea, M.; Emblico, L.; Fuzzi, S.; Ceburnis, D.; Yoon, Y. J.; O’Dowd, C. D.; Putaud, J. P.; Dell'Acqua, A. J. Geophys. Res.-Atmos. 2004, 109, D24215, DOI:10.1029/ 2004JD005137.

(15) Mochida, M.; Kitamori, Y.; Kawamura, K.; Nojiri, Y.; Suzuki, K. J. Geophys. Res.-Atmos. 2002, 107, 4325-4334.

(16) Myers, D. Surfactant Science and Technology; VCH: New York, 1988.

(17) Gill, P. S.; Graedel, T. E.; Weschler, C. J. Rev. Geophys. 1983 , 21, 903-920.

(18) Ellison, G. B.; Tuck, A. F.; Vaida, V. J. Geophys. Res.-Atmos. 1999, 104, 11633-11641.

(19) Cistola, D. P.; Hamilton, J. A.; Jackson, D.; Small, D. M. Biochem. 1988, $27,1881-1888$.

(20) De Mul, M. N. G.; Davis, H. T.; Evans, D. F.; Bhave, A. V.; Wagner, J. R. Langmuir 2000, 16, 8276-8284.

(21) Johann, R.; Vollhardt, D. Mat. Sci. Eng. C 1999, 8-9, 35-42.

(22) Andrews, E.; Larson, S. M. Environ. Sci. Tech. 1993, 27, 857865.

(23) Thornton, J. A.; Abbatt, J. P. D. J. Phys. Chem. A 2005, 109, 10004-10012

(24) Garland, R. M.; Wise, M. E.; Beaver, M. R.; Dewitt, H. L.; Aiken, A. C.; Jimenez, J. L.; Tolbert, M. A. Atmos. Chem. Phys. 2005, 5, 19511961.
(25) McNeill, V. F.; Patterson, J.; Wolfe, G. M.; Thornton, J. A. Atmos. Chem. Phys. 2006, 6, 1635-1644.

(26) Bertram, A. K.; Ivanov, A. V.; Hunter, M.; Molina, L. T.; Molina, M. J. J. Phys. Chem. A 2001, 105, 9415-9421.

(27) Molina, M. J.; Ivanov, A. V.; Trakhtenberg, S.; Molina, L. T. Geophys. Res. Lett. 2004, 31, L22104, DOI:10.1029/2004GL020910.

(28) Schauer, J. J.; Rogge, W. F.; Hildemann, L. M.; Mazurek, M. A.; Cass, G. R. Atmos. Environ. 1996, 30, 3837-3855.

(29) Limbeck, A.; Puxbaum, H. Atmos. Environ. 1999, 33, 1847-1852.

(30) Schauer, J. J.; Kleeman, M. J.; Cass, G. R.; Simoneit, B. R. T. Environ. Sci. Tech. 2002, 36, 567-575.

(31) Graham, B.; Guyon, P.; Taylor, P. E.; Artaxo, P.; Maenhaut, W. Glovsky, M. M.; Flagan, R. C.; Andreae, M. O. J. Geophys. Res.-Atmos. 2003, 108 (D24), 4766.

(32) Kawamura, K.; Ishimura, Y.; Yamazaki, K. Global Biogeochem. Cycles 2003, 17 (1), 1003

(33) Simoneit, B. R. T.; Kobayashi, M.; Mochida, M.; Kawamura, K. Lee, M.; Lim, H. J.; Turpin, B. J.; Komazaki, Y. J. Geophys. Res.-Atmos. 2004, 109, D19510, DOI: 10.1029/2004JD004598.

(34) Yue, Z. W.; Fraser, M. P. Atmos. Environ. 2004, 38, 3253-3261.

(35) Cheng, Y.; Li, S. M. Environ. Sci. Tech. 2005, 39, 2239-2246.

(36) Robinson, A. L.; Donahue, N. M.; Rogge, W. F. J. Geophys. Res.Atmos. 2006, 111, D03302, DOI: 10.1029/2005JD006265.

(37) Hearn, J. D.; Smith, G. D. J. Phys. Chem. A 2004, 108, 1001910029

(38) Smith, G. D.; Woods, E.; DeForest, C. L.; Baer, T.; Miller, R. E. J. Phys. Chem. A 2002, 106, 8085-8095.

(39) Hearn, J. D.; Lovett, A. J.; Smith, G. D. Phys. Chem. Chem. Phys $\mathbf{2 0 0 5}, 7,501-511$.

(40) Morris, J. W.; Davidovits, P.; Jayne, J. T.; Jimenez, J. L.; Shi, Q.; Kolb, C. E.; Worsnop, D. R.; Barney, W. S.; Cass, G. Geophys. Res. Lett. 2002, 29, DOI: $10.1029 / 2002$ GLO14692.

(41) Zahardis, J.; LaFranchi, B. W.; Petrucci, G. A. J. Geophys. Res. Atmos. 2005, 110 D08307, DOI: 10.1029/2004JD005336.

(42) Zahardis, J.; LaFranchi, B. W.; Petrucci, G. A. Atmos. Environ 2006, 40, 1661-1670.

(43) Ziemann, P. J. Faraday Discuss, 2005, 130, 469-490.

(44) Hung, H. M.; Katrib, Y.; Martin, S. T. J. Phys. Chem. A 2005 , $109,4517-4530$

(45) Katrib, Y.; Biskos, G.; Buseck, P. R.; Davidovits, P.; Jayne, J. T.; Mochida, M.; Wise, M. E.; Worsnop, D. R.; Martin, S. T. J. Phys. Chem A 2005, 109, 10910-10919.

(46) Katrib, Y.; Martin, S. T.; Hung, H. M.; Rudich, Y.; Zhang, H. Z.; Slowik, J. G.; Davidovits, P.; Jayne, J. T.; Worsnop, D. R. J. Phys. Chem. A 2004, 108, 6686-6695.

(47) King, M. D.; Thompson, K. C.; Ward, A. D. J. Am. Chem. Soc 2004, 126, 16710-16711.

(48) Thornberry, T.; Abbatt, J. P. D. Phys. Chem. Chem. Phys. 2004, 6 , $84-93$.

(49) Moise, T.; Rudich, Y. J. Geophys. Res.-Atmos. 2000, 105, 1466714676

(50) de Gouw, J. A.; Lovejoy, E. R. Geophys. Res. Lett. 1998, 25, $931-$

(51) Moise, T.; Rudich, Y. J. Phys. Chem. A 2002, 106, 6469-6476.

(52) Knopf, D. A.; Anthony, L. M.; Bertram, A. K. J. Phys. Chem. A 2005, 109, 5579-5589.

(53) Dubowski, Y.; Vieceli, J.; Tobias, D. J.; Gomez, A.; Lin, A.; Nizkorodov, S. A.; McIntire, T. M.; Finlayson-Pitts, B. J. J. Phys. Chem. A 2004, 108, 10473-10485.

(54) McIntire, T. M.; Lea, A. S.; Gaspar, D. J.; Jaitly, N.; Dubowski, Y.; Li, Q. Q.; Finlayson-Pitts, B. J. Phys. Chem. Chem. Phys. 2005, 7, 3605-3609.

(55) Gomez, A. L.; Park, J.; Walser, M. L.; Lin, A.; Nizkorodov, S. A J. Phys. Chem. A 2006, 110, 3584-3592.

(56) Vieceli, J.; Ma, O. L.; Tobias, D. J. J. Phys. Chem. A 2004, 108, $5806-5814$

(57) Mukerjee, P.; Mysels, K. J. Critical micelle concentrations of aqueous surfactant systems, U.S. National Bureau of Standards; for sale by the Supt. of Docs., U.S. Govt. Print. Off: Washington, 1971.

(58) Mahieu, N.; Canet, D.; Cases, J. M.; Boubel, J. C. J. Phys. Chem. 1991, 95, 1844-1846.

(59) Thornton, J. A.; Braban, C. F.; Abbatt, J. P. D. Phys. Chem. Chem. Phys. 2003, 5, 4593-4603.

(60) Tang, I. N.; Munkelwitz, H. R. J. Geophys. Res.-Atmos. 1994, 99 $18801-18808$

(61) Tang, I. N.; Tridico, A. C.; Fung, K. H. J. Geophys. Res.-Atmos. 1997, 102, 23269-23275.

(62) Cox, R. A.; Derwent, R. G. J. Photochem. 1976, 6, 23-34.

(63) DeMore, W. B.; Sander, S. P.; Golden, D. M.; Hampson, R. F.; Kurylo, M. J.; Howard, C. J.; Ravishankara, A. R.; Kolb, C. E.; Molina, M. J. Chemical Kinetics and Photochemical Data for Use in Stratospheric Modeling, 12th ed.; National Aeronautics and Space Administration Jet Propulsion Laboratory: Pasadena, CA, 1997. 
(64) Cziczo, D. J.; Abbatt, J. P. D. J. Phys. Chem. A 2000, 104, 20382047.

(65) Becker, K. H.; Kleffmann, J.; Negri, R. M.; Wiesen, P. J. Chem. Soc.-Faraday Trans. 1998, 94, 1583-1586.

(66) Hearn, J. D.; Smith, G. D. Anal. Chem. 2004, 76, 2820-2826.

(67) Brown, S. S.; Ryerson, T. B.; Wollny, A. G.; Brock, C. A.; Peltier, R.; Sullivan, A. P.; Weber, R. J.; Dube, W. P.; Trainer, M.; Meagher, J. F.; Fehsenfeld, F. C.; Ravishankara, A. R. Science 2006, 311, 67-70.

(68) Antilla, T.; Kiendler-Scharr, A.; Tillman, R.; Mentel, T. F. J. Phys. Chem. A. 2006, 110, 10435-10443.

(69) Folkers, M.; Mentel, T. F.; Wahner, A. Geophys. Res. Lett. 2003 $30,1644-1647$

(70) Langmuir, I. Proc. Natl. Acad. Sci. U.S.A. 1917, 3, 251-257.

(71) Rideal, E. K. J. Phys. Chem. 1925, 29, 1585-1588.

(72) Schofield, R. K.; Rideal, E. K. Proc. Royal Soc. 1926, 110A, 167177.

(73) Knopf, D. A.; Mak, J.; Gross, S.; Bertram, A. K. Geophys. Res. Lett. 2006, 33, L17816.

(74) Moise, T.; Talukdar, R. K.; Frost, G. J.; Fox, R. W.; Rudich, Y. J. Geophys. Res.-Atmos. 2002, 107, (D2), 4014.

(75) Docherty, K. S.; Ziemann, P. J. J. Phys. Chem. A 2006, 110, 35673577.

(76) Steinfeld, J. I.; Francisco, J. S.; Hase, W. L. Chemical Kinetics and Dynamics, 2nd ed.; Prentice Hall: Upper Saddle River, N.J., 1999.

(77) Donaldson, D. J.; Anderson, D. J. Phys. Chem. A 1999, 103, 871876 .

(78) Mmereki, B. T.; Donaldson, D. J.; Gilman, J. B.; Eliason, T. L.; Vaida, V. Atmos. Environ. 2004, 38, 6091-6103.

(79) Mmereki, B. T.; Donaldson, D. J. J. Phys. Chem. A 2003, 107, 11038-11042.
(80) Kwamena, N. O. A.; Thornton, J. A.; Abbatt, J. P. D. J. Phys. Chem A 2004, 108, 11626-11634.

(81) Poschl, U.; Letzel, T.; Schauer, C.; Niessner, R. J. Phys. Chem. A 2001, 105, 4029-4041.

(82) Ammann, M.; Poschl, U.; Rudich, Y. Phys. Chem. Chem. Phys. 2003, 5, 351-356

(83) Hanson, D. R.; Ravishankara, A. R.; Solomon, S. J. Geophys. Res.Atmos. 1994, 99, 3615-3629.

(84) Wadia, Y.; Tobias, D. J.; Stafford, R.; Finlayson-Pitts, B. J. Langmuir 2000, 16, 9321-9330.

(85) Yaws, C. L. Yaws' Handbook of Thermodynamic and Physical Properties of Chemical Compounds; Knovel: Norwich, N.Y., 2003.

(86) Schauer, J. J.; Kleeman, M. J.; Cass, G. R.; Simoneit, B. R. T. Environ. Sci. Tech. 1999, 33, 1566-1577.

(87) Setschenow, J. Z. Z. Physik. Chem. 1889, 4, 117-125.

(88) Pankow, J. F. Atmos. Environ. 1994, 28, 189-193.

(89) Seinfeld, J. H.; Pankow, J. F. Annu. Rev. Phys. Chem. 2003, 54, $121-140$.

(90) Tabazadeh, A. Atmos. Environ. 2005, 39, 5472-5480.

(91) Atkins, P. W. Physical Chemistry, 5th ed.; W. H. Freeman \& Co.: New York, 1994.

(92) Tester, J. W.; Modell, M. Thermodynamics and Its Applications, 3rd ed ed.; Prentice Hall PTR: Upper Saddle River, N.J, 1997.

(93) Donahue, N. M.; Hartz, K. E. H.; Chuong, B.; Presto, A. A.; Stanier, C. O.; Rosenhorn, T.; Robinson, A. L.; Pandis, S. N. Faraday Discuss 2005, $130,295-309$.

(94) Offenberg, J. H.; Kleindienst, T. E.; Jaoui, M.; Lewandowski, M.; Edney, E. O. Geophys. Res. Lett. 2006, 33, L03816. 